\title{
Genes termorregulados diferencialmente expressos em Conidiobolus lamprauges
}

\author{
Thermoregulated genes differentially expressed in Conidiobolus lamprauges
}

\author{
Josiane Aparecida Gonçalina da Silva ${ }^{\mathrm{I}}$ Daphine Ariadne Jesus de Paula ${ }^{\mathrm{I}}$ Marcelo Marques da Silveira ${ }^{\mathrm{I}}$ \\ Maria Cristina da Silva ${ }^{I}$ Laila Natasha Santos Brandão ${ }^{I}$ Leticia Camara Pitchenin ${ }^{I}$ \\ Luciano Nakazato $^{\mathrm{I}}$ Valéria Dutra $^{\mathrm{I}^{*}}$
}

\begin{abstract}
- NOTA-
RESUMO

Conidiobolus lamprauges é um fungo zigomiceto patógeno de humanos e animais, causador da

at $37^{\circ} \mathrm{C}$. This gene performs functions related to pathogenicity during host-pathogen interaction process in several pathogenic microorganisms. showing a potential involvement in hostpathogen relationship, and virulence in C. Iamprauges.
\end{abstract} \begin{abstract}
conidiobolomicose, caracterizada por uma rinossinusite crônica granulomatosa severa. A capacidade de se adaptar e crescer a altas temperaturas são sugeridos como um atributo de virulência em fungos que infectam animais e humanos, no entanto, em C. lamprauges, pouca informação é disponível sobre esse aspecto. $O$ objetivo deste trabalho foi identificar genes com expressão diferencial em $\boldsymbol{C}$. lamprauges cultivado a $30^{\circ}$ e $37^{\circ} \mathrm{C}$ através da técnica de Análise de Diferença Representacional (RDA). Após análise e sequenciamento de um conjunto de 120cDNAs, identificou-se uma enzima glicolítica denominada enolase, diferencialmente expressa a $37^{\circ} \mathrm{C}$. Esse gene exerce funções relacionadas à patogenicidade no processo de infecção em diversos micro-organismos patogênicos, apresentando um potencial de envolvimento na relação patógeno-hospedeiro e virulência em $\boldsymbol{C}$. lamprauges.
\end{abstract}

Palavras-chave: expressão diferencial, enolase, C. lamprauges.

\section{ABSTRACT}

Conidiobolus lamprauges is a pathogen zygomycetes fungi of humans and animals, responsible for conidiobolomycosis, which is characterized by a severe granulomatous chronic rhinosinusitis. The ability to adapt and grow at high temperatures is suggested as an attribute of virulence in fungi that infect animals and humans, however regarding $\boldsymbol{C}$. lamprauges little information is available about this aspect. This paper aims to identify differential expression genes in C. lamprauges grown at $30^{\circ} \mathrm{C}$ and $37^{\circ} \mathrm{C}$ through the technique of Representational Difference Analysis (RDA). After the analysis and sequencing of a set of $120 \mathrm{cDNAs}$, it was identified enolase, a glycolytic enzyme, differentially expressed
Key words: differential expression, enolase, C. lamprauges.

Conidiobolus spp. é um fungo sapróbio, pertencente à classe dos zigomicetos, causador da conidiobolomicose, caracterizada principalmente por rinossinusite crônica granulomatosa severa, anorexia, perda de peso, tumefação nasal, descarga nasal mucohemorrágico, dispneia e óbito (HOOGENDIJK, et al., 2006; SILVA et al., 2007; BOABAID et al., 2008). As principais espécies patogênicas são: $\boldsymbol{C}$. coronatus, $\boldsymbol{C}$. incongruus e C. lamprauges (DE PAULA et. al., 2010). No Brasil, a doença é endêmica no rebanho ovino da região Nordeste e nas regiões Sul e Centro-Oeste, sendo que o número de casos vem aumentando (SILVA et al., 2007; BOABAID et al., 2008; PEDROSO, et. al., 2009; DE PAULA et. al., 2010). Nos surtos em ovinos, a doença pode se apresentar 100\% letal (SILVA et al., 2007). Em humanos, a demora no diagnóstico contribui para o agravamento do quadro, levando, muitas vezes, à utilização de tratamentos empíricos e prolongados, que, na grande maioria dos casos, mostram-se ineficazes, principalmente porque nenhum medicamento testado até o momento foi totalmente eficaz no tratamento de infecções por Conidibolus spp., quando utilizado individualmente (KIMURA et al., 2011).

\footnotetext{
'Laboratório de Microbiologia Veterinária e Biologia Molecular, Universidade Federal de Mato Grosso (UFMT), 78060-900, Cuiabá, MT, Brasil. E-mail: valdutra@ufmt.br. *Autor para correspondência.
} 
Em fungos patogênicos, como Criptococcus neoformans e Candida albicans, a adaptabilidade e resistência à temperatura corporal dos mamíferos representa um atributo de virulência do micro-organismo, e estudos sobre o cultivo em altas temperaturas, possivelmente, possa levar ao entendimento de quais fatores moleculares tornam o fungo um patógeno de mamíferos (PERFECT, 2005; ROBERT \& CASADEVALL, 2009). Porém, dados sobre C. lamprauges são escassos. O objetivo deste trabalho foi detectar genes diferencialmente expressos termorregulados em C. lamprauges, cultivado a 30 e $37^{\circ} \mathrm{C}$, que possam estar relacionados ao processo de interação patógeno-hospedeiro.

O estudo foi conduzido com um isolado clínico de C. lamprauges, identificado e classificado previamente por DE PAULA et al. (2010). Para construção das bibliotecas de cDNA, o microorganismo foi cultivado em meio Agar Sabouraud Dextrose durante 4 dias, sendo as temperaturas de $37^{\circ} \mathrm{C}$ e $30^{\circ} \mathrm{C}$ denominadas tester e driver, respectivamente. O RNA foi extraído de acordo com SOKOLOVSKY et al. (1990). O cDNA foi sintetizado utilizando o sistema SMARTer ${ }^{\text {TM }}$ PCR cDNA Synthesis Kit (Clontech) com $1 \mu \mathrm{g}$ de RNA total. Uma alíquota de $5 \mu \mathrm{L}$ da primeira fita foi utilizada como molde para a síntese da segunda fita e a técnica de RDA foi realizada segundo o protocolo descrito por DUTRA et al. (2004).

Para obtenção dos produtos diferenciais das duas hibridizações, denominados PD1 e PD2, o cDNA de cada condição foi digerido com a enzima de restrição Sau3AI (New England BioLabs) e duas etapas sucessivas de hibridização $\left(67^{\circ} \mathrm{C}\right.$ por $\left.18 \mathrm{~h}\right)$ foram realizadas, utilizando dois pares de adaptadores (NBam 12/24 e RBam 12/24) ligados à população tester, nas proporções tester/driver de 1:10 e 1:100, respectivamente.

O PD2 do RDA foi clonado no vetor $p G E M$ T Easy (Promega) e transformado em Escherichia coli XL1 Blue, de acordo com SAMBROOK \& RUSSEL (2001). A presença de insertos foi verificada por PCR e, após a seleção dos recombinantes, as amostras foram preparadas e encaminhadas para o sequenciamento automático no MegaBace 1000 (GE Healthcare), utilizando os primers correspondentes ao vetor $p G E M$ T Easy. As ESTs obtidas foram analisadas no banco de dados do GenBank (http://www.ncbi.nlm.nih.gov) através do programa $t B L A S T x$ (ALTSCHUL et al., 1997). A classificação funcional das proteínas encontradas foi feita através do programa Gene Ontology (www.geneontology.org). Um gene de interesse identificado pelo RDA foi validado através da técnica de PCR em Tempo Real (qPCR). As reações foram realizadas em triplicata, utilizando-se SYBR Green qPCR Supermix (Invitrogen), contendo $2 \mu \mathrm{lde}$ cDNA e $5 \mathrm{pmol}$ de cada primer. As reações foram realizadas com temperatura inicial de $50^{\circ} \mathrm{C}$ por 2 minutos, seguido por 10 minutos a $95^{\circ} \mathrm{C}$. Após 40 ciclos de $95^{\circ} \mathrm{C}$ a 15 segundos, seguidos de anelamento e síntese a $60^{\circ} \mathrm{C}$ por um minuto. A curva de melting foi analisada e a expressão relativa dos genes foi baseada no método 2- $\Delta \Delta$ CT (LIVAK e SCHMITTGEN, 2001), utilizando o gene actina (DE PAULA, et al., 2011) como normalizador. Cento e vinte clones foram selecionados aleatoriamente para sequenciamento. A maioria das proteínas foram identificadas como hipotéticas e uma enzima relacionada à via glicolítica, a enolase (acesso GenBank -FE859532.1), foi identificada com nível de expressão diferencial a $37^{\circ} \mathrm{C}$. Essa enzima já tem sido descrita em outros micro-organismos patogênicos (ANGIOLELLA, et al., 1996; PAL-BHOWMICK et al., 2007; NOGUEIRA, et al., 2010). A Análise de qPCR confirmou a superexpressão de 8,27 vezes deste gene, quando o fungo foi cultivado a $37^{\circ} \mathrm{C}$.

A enolase é uma das enzimas metabólicas mais expressas no citoplasma, identificada em diversos micro-organismos, com isso, sua localização e funções celulares vêm sendo estudadas, demonstrando que, além de sua atividade glicolítica inata, desempenha importante papel em várias funções biológicas, fisiopatológicas e de superfície (PANCHOLI, 2001).

Em C. albicans, além de sua localização predominantemente citoplasmática, a enolase é uma proteína ativa integrante da parede celular, sendo um importante componente responsável pela detecção desse fungo pelo sistema imune do hospedeiro, tanto na resposta imune humoral, quanto na mediada por células. A sua detecção e de seus anticorpos circulando em pacientes com candidíase invasiva é considerada útil no monitoramento do crescimento do fungo in vivo, demonstrando ser um marcador potencialmente vantajoso no diagnóstico dessa enfermidade (ANGIOLELLA et al., 1996).

No fungo dimórfico Paracoccidiodes brasiliensis, a enolase foi diferencialmente expressa na condição de adesão ao colágeno e à fibronectina, e identificada na superfície de células leveduriformes. Essa espécie seria capaz de adquirir atividade proteolítica após a ligação da enolase ao plasminogênio e a sua conversão à plasmina, facilitando a invasão tecidual no hospedeiro, contribuindo para patogenicidade do fungo (NOGUEIRA, et al., 2010).

Em Saccharomyces cerevisiae, o gene que codifica enolase é também induzido a temperaturas elevadas e está envolvido na tolerância térmica e controle do crescimento desse organismo (IIDA \& 
YHARA, 1985). O papel dessas proteínas não se restringe a uma resposta ao choque térmico simplesmente, mas elas podem fazer parte do processo de adaptação para a sobrevivência do micro-organismo no hospedeiro (BURNIE et al., 2005).

No protozoário Plasmodium yoelli, a enolase desempenha diversas funções biológicas nãoglicolíticas, sendo avaliada como um possível alvo de drogas para o tratamento da malária (PAL-BHOWMICK et al., 2007).

O estudo concluiu que a técnica de RDA foi eficiente na obtenção de genes diferencialmente expressos e que a exposição à temperatura elevada possivelmente esteja associada à superexpressão da enolase em C. lamprauges, cujo papel no processo de interação patógeno-hospedeiro em diversos microorganismos patogênicos já foi descrito. Com isso, sua função, bem como sua localização celular em $\boldsymbol{C}$. lamprauges, deve ser elucidada.

Pesquisas que buscam compreender melhor a biologia do fungo e a identificação de genes com característica de expressão diferencial, como a enolase, são importantes, pois, após estudos adicionais estabelecendo o papel funcional para esse gene em $\boldsymbol{C}$. lamprauges, alternativas diagnósticas, de tratamento ou monitoramento podem surgir até mesmo como perspectiva de um marcador diagnóstico que contribua na avaliação da evolução da doença.

\section{AGRADECIMENTOS}

À Fundação de Amparo à Pesquisa do Estado de Mato Grosso (FAPEMAT) e ao Conselho Nacional de Desenvolvimento Científico e Tecnológico (CNPq), pelo financiamento.

\section{REFERÊNCIAS}

ANGIOLELLA, L. et al. Identification of a Glucan-Associated Enolase as Main Cell Wall Protein of Candida albicans and an Indirect Target of Lipopeptide Antimycotics. Journal of Infectious Diseases, v.173, p.684-690, 1996. Disponível em: <http://jid.oxfordjournals.org/content/173/3/684.long $>$. Acesso em: 10 jun. 2011. doi: 0022-1899/96/7303-0023.

ALTSCHUL, S.F. et al. Gapped BLAST and PSI-BLAST: a new generation of protein database search programs. Nucleic Acids Research, v.25, p.3389-3402,1997. Disponível em: <http:// www.ncbi.nlm.nih.gov/pmc/articles/PMC146917/pdf/ 253389.pdf>. Acesso em: 09 jul.2011.

BURNIE, J.P. et al. Fungal heat-shock proteins in human disease. FEMS Microbiology, v.30, p.53-88, 2005. Disponível em: <http://onlinelibrary.wiley.com/doi/10.1111/j.15746976.2005.00001.x/pdf>. Acesso em: 9 ago. 2011. doi:10.1111/j.1574-6976.2005.00001.x.
BOABAID, F.M. et al. Conidiolomycosis in sheep in the state of Mato Grosso, Brazil. Pesquisa Veterinária Brasileira, v.28, n.1, p.77-81, 2008. Disponível em: <http://www.scielo.br/ pdf/pvb/v28n1/a12v28n1.pdf $>$. Acesso em: 15 mar. 2010.

DE PAULA, D.A. et al. Molecular characterization of ovine zygomycosis in central western Brazil. Journal Veterinary Diagnostic Investigation, v.22, p.274-277, 2010. Disponível em: <http://vdi.sagepub.com/content/22/2/274.full.pdf + html $>$. Acesso em: 15 mar. 2010. doi: 10.1177/104063871002200220.

DE PAULA, D.A. et al. Identificação de genes diferencialmente expressos por Cryptococcus Gatti através da técnica de RDA durante a privação de ferro. In CONGRESSO BRASILEIRO DE MICROBIOLOGIA, 26., 2011, Foz do Iguaçu, PR. Anais... Foz do Iguaçu: SBM, 2011. Resumo 1816-2.

DUTRA, V. et al. Application of representational difference analysis to identify sequence tags expressed by Metarhizium anisopliae during the infection process of the tick Boophilus microplus cuticle. Research in Microbiology, v.155, p.245251, 2004. Disponível em: <http://linkinghub.elsevier.com/ retrieve/pii/S0923-2508(04)00003-8>. Acesso em: 7 jul. 2010.

HOOGENDIJK, C.F. et al. Rhino-orbitocerebral entomophthoramycosis. International Journal of Oral and Maxillofacial Surgery, v.35, p.77-280, 2006. Disponível em: <http://www.sciencedirect.com/science/ article/pii/S0901502705002675>. Acesso em: 5 mar. 2010.

IIDA, H.; YAHARA, I. Yeast heat-shock protein of $\mathrm{Mr} 48,000$ is an isoprotein of enolase. Nature, v.315, p.688-690, 1985. Disponível em: <http://www.nature.com/nature/journal/v315/ n6021/abs/315688a0.html>. Acesso em: 16 jan. 2012.

KIMURA, M. et al. Disseminated human connidiobolomycosis due to Conidiobolus lamprauges. Journal of Clinical Microbiology, v.49, p.752-756, 2011. Disponível em: <http:/ /www.ncbi.nlm.nih.gov/pmc/articles/PMC3043483/pdf/ zjm752.pdf>. Acesso em: 12 jan. 2012.

LIVAK, K.J.; SCHMITTGEN, T.D. Analysis of relative gene expression data using real-time quantitative PCR and the 22DDCT method. Methods, v.25, p.402-408, 2001. Disponível em: <http://www.sciencedirect.com/science/article/ pii/S1046202301912629>. Acesso em: 15 ago. 2011.

NOGUEIRA, S.V. et al. Paracoccidioides brasiliensis enolase is a surface protein that brinds plasminogen and mediates interaction of yeast forms with host cells. Infection and Immunity, v.78, n.9, p.4040-4050, 2010. Disponível em: $<$ http://www.ncbi.nlm.nih.gov/pmc/articles/PMC2937444/pdf/ 0221-10.pdf>. Aceso em: 22 jun. 2011. doi:10.1128/ IAI.00221-10.

PAL-BHOWMICK, I. et al. Sub-cellular localization and posttranslational modifications of the Plasmodium yoelii enolase suggest moonlighting functions. Malaria Journal, v.6, n.45, p.1-16, 2007. Disponível em: <http://www.ncbi.nlm.nih.gov/ pmc/articles/PMC1868031/pdf/1475-2875-6-45.pdf>. Acesso em: 17 jul. 2010 . doi: 10.1186/1475-2875-6-45.

PANCHOLI, V. Multifunctional a-elonase: its role in diseases. Cellular and Molecular Life Sciences, v.58, p.902-920. 2001. Disponível em: <http://www.springerlink.com/content/ 101193/>. Acesso em: 9 set. 2011. doi: 1420-682X/01/07090219. 
PEDROSO, P. et al. Rinite micótica rinofaríngea em um ovino Texel no Rio Grande do Sul. Acta Scientiae Veterinariae, v.37, p.181-185, 2009. Disponível em: <http:// www.sovergs.com.br/conbravet2008/anais/cd/resumos/R11502.pdf>. Acesso em: 5 mar. 2010.

PERFECT, J.R. Cryptococcus neoformans: a sugar-coated killer with designer genes. Immunology and Medical Microbiology, v.45, p.395-402, 2005. Disponível em: <http://onlinelibrary.wiley.com/ doi/10.1016/j.femsim.2005.06.005/pdf>. Acesso em: 15 jul. 2011.

ROBERT, A.V.; CASADEVALL, A. Vertebrate endothermy restricts most fungi as potential pathogens. Journal of Infectious Diseases, v.200, p.1623-1626, 2009. Disponível em: <http:// jid.oxfordjournals.org/content/200/10/1623.full.pdf + html $>$. Acesso em: 19 jan. 2012. doi: 10.1086/644642.

SAMBROOK, J.; RUSSEL, D.W. Molecular cloning: a laboratory manual. New York: Cold Spring Harbor laboratory, 2001. 253p.

SILVA, S.M.M.S. et al. Conidiobolomycosis in Sheep in Brazil. Veterinary Pathologhy, v.44, p.314-319, 2007. Disponível em: <http://vet.sagepub.com/content/44/3/314.full.pdf + html $>$. Acesso em: 20 fev. 2010.

SOKOLOVSKY, V.R. et al. Fast and reliable mini-prep RNA extraction from Neurospora crassa. Fungal Genet Newsllet, v.37, p.41-43, 1990 